\title{
Dossiê
}

\footnotetext{
Resumo

Pensar o fracasso escolar como acontecimento do sujeito subverte o discurso do fracasso produzido em grande medida pelo fantasma da avaliação "standard" na gestão do ensino. Nessa perspectiva, interrogam-se o furor avaliativo e os discursos acerca da eficácia e qualidade dos sistemas educacionais enquanto dispositivos de domesticação social dos mais novos que acabam por aumentar a psicologização e a medicalização no cotidiano escolar.

Descritores: avaliação educacional; fracasso escolar; educação; psicanálise.
}

\section{PRODUÇÃO DO \\ FRACASSO ESCOLAR E \\ O FUROR AVALIATIVO: O SUJEITO RESISTE?}

Eric Ferdinando Kanai Passone

DOI: http://dxdoi.org/10.11606/issn. 1981-1624.v20i3p400-420.

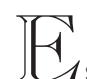

4 ste artigo apresenta uma reflexão teórica sobre o tema avaliação na atualidade, em especial, acerca da avaliação "estandardizada" presente na educação escolar, tendo como base a pesquisa "Da avaliação da educação básica aos incentivos por resultados: uma abordagem pelo discurso psicanalítico". Tal pesquisa buscou identificar os efeitos da avaliação externa da política educacional sobre o ato educativo, no âmbito da educação básica, a partir da análise das práticas discursivas e entrevistas com profissionais de diversas escolas (professores, coordenadores e diretores de escolas). Tratou-se, especificamente, de conhecer os efeitos da demanda de avaliação associada à produtividade da escola, em que os profissionais da educação são avaliados conforme o rendimento dos alunos em testes e podem ou não receber algum "bônus" no salário, de acordo com as metas satisfeitas.

- Psicanalista. Doutor em Educação pela Universidade Estadual de Campinas (Unicamp). Pós-doutorando no Laboratório de Estudos e Pesquisas Psicanalíiticas e Educacionais sobre a Infância da Faculdade de Educação da Universidade de São Paulo (LEPSI IP/FE-USP), São Paulo, SP, Brasil. 
No âmbito das reformas educacionais, que de acordo com Freitas (2014) deveríamos chamar de "reformas empresariais", tais propostas são relativamente recentes, como observamos nos casos do estado de São Paulo, com a criação do Programa Qualidade na Escola e do IDESP (Índice de Desenvolvimento da Educação de São Paulo); os estados, Ceará, Espírito Santo, Minas Gerais, Pernambuco e Rio de Janeiro, também possuem programas próprios de incentivos financeiros articulados em torno dos resultados escolares e do desempenho do aluno.

Refere-se, por um lado, a um dispositivo composto por um conjunto de ações no âmbito da gestão dos recursos humanos e da orientação pedagógica, como currículo básico, programas pedagógicos, livros didáticos, testes e avaliação de desempenho, dispositivo que tanto cifra o aluno em seu suposto "valor" quanto responsabiliza a escola e os profissionais pelos resultados obtidos. Por outro, a avaliação opera uma substituição do jogo transferencial entre o professor e o aluno por um conjunto de normas e métodos externos, em que o desejo torna-se puro desejo de funcionalidade.

Tal lógica não somente nega a realidade da educação, como também acaba por inverter a demanda escolar, na medida em que são os professores que passam a depender de seus alunos ao ficarem reféns do engajamento ou não das suas turmas na preparação e realização dos testes de desempenho, revelando um estado perverso no qual os adultos acabam literalmente governados pelos mais novos, uma das marcas do atual "mal-estar" na educação contemporânea e da degradação que vem ocorrendo nos laços sociais no cotidiano escolar. $\mathrm{O}$ fato de alguns alunos e algumas turmas se negarem a participar das avaliações, como relataram os entrevistados, revela que algo não vai tão bem no plano das certezas administrativas, em que a promessa da transmissão de ensino se inclina cada vez mais para o domínio da submissão e da insubmissão. A recusa de um sentido imposto ligado à ignorância daquilo que poderia fazer sentido cria um não-sentido contagioso.

O aumento de interesses sobre os dispositivos de avaliação, gestão e responsabilização de professores e escolas públicas reflete o atual domínio técnico sobre o mundo da política, em que os valores 
e ideais educacionais perseguidos no debate político dos últimos séculos vão sendo minados em nome da racionalidade lógica-formal representada pela medida e pelo custo e benefício, isto é, regido pela lógica gerencial e utilitarista que domina a política educacional no mundo ocidental e globalizado. As agências de avaliação constituem atualmente numa nova maneira de dar as ordens e de fazer política, um modo de controle pelos números bastante sutil que se legitima a partir do discurso da transparência e da qualidade dos serviços (Gori, 2011). Um modo de fazer política sem fazê-lo, marca da prefiguração dessa passividade em que a vida social é reduzida a padrões impostos, sem ser criada e recriada pela troca da palavra.

Paralelamente, como efeito da crescente demanda de avaliação e resultados na educação, a escola testemunha o esvaziamento simbólico no campo educacional (Dufour, 2005), em que a lógica da medida e dos indicadores estatísticos surge como valor supremo, como univocidade discursiva acerca da qualidade educacional. Segundo Gori (2014), a desvalorização incessante do saber narrativo em proveito do saber tecnicocientífico e informacional constituiu-se como assinatura do Ocidente desde o começo, mas jamais se imaginou, mesmo com o desenvolvimento do capitalismo, que a racionalidade técnica se imporia como uma ética de vida, sintoma de nossa cultura, definindo condutas e costumes morais. Para esse autor, uma das formas de combater o "furor avaliativo" de nossos tempos é interrogarmos acerca da noção de valor produzido por essa nova "forma de ditadura que são os números", que domina nosso desgastado contrato social.

No entanto, o que quer dizer "avaliar"? No senso comum o termo significa "determinar um valor", e podemos dizer com Nietzsche que o ser humano é 
um "animal avaliador", no sentido que o filosofo deu a etimologia da palavra alemã Mensch (homem) como "aquele que avalia". Para o filósofo "criar é avaliar", na medida em que a natureza não possui valor, quem cria valor é o homem, fundamento da crítica que endereça à moral metafísica e científica como fonte de toda "vontade de verdade" e contra o "absolutismo de valores" (Machado, 1997, p. 69). Ao se indagar sobre o valor dos valores propõe um critério de avaliação que não possa ser avaliado moralmente, a própria vida, cujo valor só pode ser criado na experiência singular de cada vida. Como afirma Nietzsche (1985): 'É preciso estender os dedos, completamente, nessa direção e fazer o ensaio de captar essa assombrosa finesse-de que o valor da vida não pode ser avaliado" (p. 21).

No campo educacional, podemos dizer que a avaliação e comparação do aprendizado dos alunos nos remetem ao igualitarismo religioso de La Salle, no final do século XVII e início do XVIII, quem impôs uma organização minuciosa dos tempos e espaços escolares e a avaliação do rendimento, com o objetivo de conhecer o nível de aprendizagem dos alunos. Jerusalinsky (1999) lembra que a proposta de "padronizar a educação, ao estabelecer um rendimento suposto como necessário, determinou um eixo com relação ao qual todas as crianças ficam comparadas" (p. 179). A medida avaliativa parte do suposto de que todas as crianças de tal idade devem aprender de acordo com um padrão, criando um critério de normalidade, produzindo por contraste tanto uma psicopatologia das aprendizagens como uma psicopatologia da adaptação escolar (Jerusalinsk, 1999).

Com a pedagogia moderna a avaliação foi progressivamente integrada ao conhecimento da aprendizagem e é impossível pensarmos qualquer tipo de aprendizagem que não recorra há algum tipo de juízo, para verificar alguma competência peculiar que necessita de reconhecimento e aprovação. Não se trata aqui de questionar aquilo que poderíamos chamar outrora de uma "avaliação banal", ou aquela necessária à criação de um aluno, isto é, como meio do sujeito se alienar e se separar do Outro. A avaliação como atividade meio do processo escolar, e não como fim. De modo contrário, a avaliação "standard" ou "avaliação externa", tanto nacional como internacional, caracteriza-se pela utilização de dados estatísticos e classificação sistemática do rendimento, pela atribuição de 
sanções aos profissionais e escolas e pela ênfase nos produtos e resultados, em que a aquisição de saber deixa de ser um fim do processo educacional e passa a ser um meio para atingir os resultados e metas. A finalidade da escolarização reduzida ao imaginário homogeneizante das metas e resultados considerados "adequados" não seria, no mínimo, contraditória em relação ao discurso de inclusão educacional, que possui como fundamento o respeito às diferenças individuais, aos diferentes tempos e ritmos dos alunos e às diferentes formas de apreensão e elaboração dos conhecimentos?

Como fantasma de nossa época, a avaliação tornou-se um poderoso mecanismo de produção de "valor" sobre o objeto, um sintoma de nossa civilização orientada racionalmente à quantificação e mercantilização da vida. Ela é ao mesmo tempo um dispositivo e um sintoma de um modo de controle social particularmente perigoso: tornar tudo e todos contabilizáveis. Pode-se dizer que a avaliação marca o imaginário social como um fantasma de nossos tempos. O trabalho na clínica com crianças, adolescentes e jovens, como aponta Tyszler (2014, p. 147), indica que não se trata mais da fantasia "Bate-se numa criança" - "Sou batido", como destacado por Freud em 1919, estamos hoje na lógica do "fantasma codificado": "Avalia-se uma criança" - "Sou avaliado", com toda carga de satisfação narcísica e gozo que comporta essa fantasia. Nesse sentido, o confronto entre psicanálise e a avaliação era inevitável, uma vez que a psicanálise trata o ser no seu estado de ser único, insubstituível, enquanto a avaliação produz o ser mensurável, comparável e substituível, isto é, como objeto na série de gozo do Outro.

O mundo criado pelo poder é um mundo de uniformidade, como assinala Enriquez (1990), em que todo poder aspira ao universal e ao invariável, ao homogêneo. No entanto, como lembra Birman (2014), o próprio Freud destacou que o "homem não aceitaria e resistiria sempre à homogeneização do seu ser e manteria a sua diferença face ao outro como signo maior de sua condição ética e política" (p. 39). No ensaio, "Análise com 
fim e análise sem fim" (1937/1996), Freud concluiu que governar, educar e psicanalisar constituem-se como práticas impossíveis, na medida em que o sujeito resistiria a qualquer tentativa do outro de homogeneizá-lo ou de pretender apagar a marca de sua singularidade, testemunho do inconsciente sexual e infantil constitutivo de nossas práticas sociais, quanto de suas possibilidades históricas e libidinais.

\section{Os discursos acerca da avaliação da educação básica}

Nas sociedades de massas e nas democracias modernas, a avaliação tornou-se uma espécie de "Novo Evangelho" para os administradores e políticos, uma crença que tem dominado as decisões públicas das democracias modernas. Sob o semblante do discurso científico, a avaliação surgiu no interior do Estado como um Cavalo de Troia, isto é, um aparato destrutivo cuja função consiste em minar uma cultura e instaurar uma nova ordem na administração dos "negócios" do Estado. A engrenagem da avaliação é indissociável ao plano da reforma administrativa do Estado, em que a lógica gerencial das empresas tomou de assalto a cultura do serviço público, em direção ao Estado-Estratégico, isto é, um Estado que acolhe no coração de suas decisões o modus operandi e as regras do mercado.

No campo da política educacional, os sistemas de ensino tornaram-se cada vez mais padronizados e buscam resultados e rendimentos de acordo com os designíos do mercado e da economia globalizada. A produção teórica sobre a temática 
encontra-se predominantemente no campo da avaliação, gestão e políticas educacionais. Em artigo em que propomos analisar parte dessa literatura constatou-se a polêmica entre pesquisadores acerca da eficácia dos programas de incentivos monetários para professores (Passone, 2014b). Dentre os materiais analisados, verificou-se que os discursos oscilam entre dois extremos, por um lado, os discursos que se posicionam críticos a tais propostas, buscando investigar os reflexos da reforma política sobre a organização da educação e do ensino (Freitas, 2013, 2014; Ravitch, 2010). Por outro, encontram-se os que defendem sua implementação e aprimoramento como meio de agregar qualidade educacional por meio da responsabilização dos profissionais (Broocke, 2008, 2013; Pontual, 2010).

De um modo geral, o modelo dos incentivos é considerado um mecanismo administrativo oriundo das práticas gerenciais de empresas que passou a operar no setor educacional a partir do neoliberalismo. A fórmula é bem simples: a remuneração atrelada aos resultados motivariam os professores a trabalharem mais e melhor. Nota-se, também, uma variedade de termos técnicos utilizados para descrever tais programas ou mecanismos de incentivos monetários para docentes e escolas, tais como: "pagamento por performance"; "pagamento por desempenho"; "remuneração variável"; "remuneração por desempenho"; "incentivos e bonificação monetários"; e, "bonificação por mérito” (Broocke, 2013; Bonamino \& Sousa, 2012).

Evidentemente, tais denominações não são escolhas aleatórias, mas remetem às distintas áreas epistêmicas de conhecimento que compõem o campo das ciências da educação e das ciências econômicas e administrativas. O que parece velado no debate é que, seja na área da economia ou da educação, os "incentivos monetários" ou "estímulos" para professores possuem em comum os pressupostos das teorias motivacionais do comportamento, muito comum ao ideário das escolas administrativas de desenvolvimento "gerencial". A tese psicofisiológica velada e implícita nos termos comumente utilizados nos discursos dominantes das políticas educacionais nos remete 
às teorias de motivação comportamental, originalmente desenvolvidas por Watson e, posteriormente, "humanizadas" por Maslow e Herzberg, dentre outros. Tais abordagens estabelecem a relação entre necessidades psicofisiológicas do organismo e a "motivação" do indivíduo. A motivação é o resultado de estímulos e satisfação de necessidades e recompensas, sendo tais recompensas associadas às necessidades fisiológicas e sociais, reduzindo a condição humana à dimensão biológica do organismo, desconsiderando a dimensão singular de cada pessoa, isto é, sua dimensão particular como sujeito de desejo. Torna-se fundamental apontar para essa diferença radical entre a noção de motivação, como processo estímulo-resposta na relação indivíduo-ambiente e o que é da ordem do desejo, isso que se inscreve em um processo da própria história - sexual e inconsciente - do sujeito. O que é da ordem da necessidade do ser humano passa necessariamente pela ordem da contingência pulsional-cultural, isto é, pela demanda e do desejo do Outro, desviando-se do registro meramente biológico por meio da nossa estrutura de linguagem e de sua articulação com a pulsão. O objeto da necessidade, ao se articular com a linguagem e a pulsão, adquire novo status: o de objeto perdido e sempre visado pelo desejo e ao mesmo tempo impossível. Portanto, o que está em jogo é o objeto causa de desejo e não o objeto em si, como propõem as abordagens que conferem consistência real ao objeto de conhecimento. Como Lacan (1997) observou acerca do discurso da ciência, que ao produzir seu próprio objeto de saber, alicerçada no ideal do saber absoluto e universal, a ciência apaga o sujeito, marca da suspensão da função simbólica como metáfora constitutiva da subjetividade humana. A predominância do discurso científico responde em grande parte por essa função de produzir um conhecimento, que é demandado pela gestão das políticas educacionais, pelos políticos, pelo mercado informacional, pela economia globalizada.

$\mathrm{Na}$ literatura sobre gestão educacional, destacam-se as críticas com relação à promoção de mecanismos de mercado no interior do espaço estatal, na linha do pragmatismo e dos princípios da New Public Management norte-americana, como 
extensão das ideias da gestão privada ao setor público, que subordina os direitos sociais e de cidadania à lógica do mercado, em que passa a prevalecer a competição e a produtividade, normalmente propagadas por meio de discursos sobre eficácia, eficiência e qualidade. Paralelamente, a tecnocracia amplia seu poder sobre o saber-fazer dos professores, que acaba por desqualificar e desautorizar cada vez mais a função do educador. Como diz um professor entrevistado, em relação às políticas educacionais contemporâneas, "não temos mais dúvidas nenhuma, estamos sendo sistematicamente desautorizados, sistematicamente retirados do centro do processo educativo" (Passone, 2014a). Se, por um lado, temos um discurso social contínuo acerca da importância da escola e da educação para a sociedade, tendo a figura do professor como principal sujeito desse processo, por outro, as práticas discursivas dos profissionais sugerem ao contrário, a sua retirada de cena, ou, como relatou outro professor: "eu sinto um sentimento de impotência muito grande, uma frustração muito grande, por que nós não servimos mais pro sistema".

\section{Vale o quanto ensina? Novas formas de servidão}

Sob a globalização econômica e financeira, assiste-se à dominância do discurso capitalista no campo da educação. Isso implica pensar que o laço sócio-histórico produzido em torno da política educacional, que tem como referência a escola "laica, obrigatória e gratuita" destinada à formação cultural de crianças e adolescentes e à formação de cidadãos, portanto, de laços sociais, corre o risco de se tornar inoperante perante o mestre capitalista. Essa relação econômica com o saber, efeito desse discurso, inscreve o ato educacional enquanto um produto em termos de mercado, em que a avaliação cifra o valor de cada um no sistema de trocas. Como destacado em outro artigo, o aspecto econômico da 
educação, como formação de "capital humano”, passa a ser cifrado (\$) e contabilizado em termos de mercado, em que o conhecimento se transforma objetivamente em valor monetário, característica central de nossa "sociedade do conhecimento" (Passone, 2013b). Assim, assiste-se à migração das técnicas administrativas de mercado para a administração pública, com os critérios de eficácia, avaliação e os padrões "ISO de qualidade", produtividade e competitividade inerentes aos serviços privados sendo aplicados no campo das políticas educacionais públicas.

De modo alusivo, pode-se destacar a fala uma diretora que destacou a "criança como uma moeda de troca", para lembrar que no sistema atual de ensino o "professor vale o quanto ensina". Outra profissional, ao se referir à criança no processo avaliativo, orgulhosa diante de seu aluno, considerava-o como "um tesouro cravejado de diamantes". Bom, logo devemos nos indagar: quando uma criança não é considerada um "tesouro”, ela é considerada o quê?

Indubitavelmente, podemos dizer que chegamos ao ápice daquilo que Lacan (2008) bem chamou de "absolutização do mercado de saber", em que a lógica da "satisfação garantida ou seu dinheiro de volta" passou a reinscrever o papel do Estado e da própria educação, ameaçando tudo o que se inscreve como laço social. Na realidade 
econômica em que se encontram as coisas, avaliar supõe determinar um valor à criança, tornando-a um bem, um objeto de troca, na medida em que seu "trabalho" pode implicar um plus monetário para a escola. Lembremos, conforme ele afirmou, que será na "brecha" entre o sujeito do valor de troca perante seu valor de uso "que se produz e cai a chamada mais-valia" (p. 21), esta entendida como mais-gozar para o psicanalista. A ideia de que a criança é um valor mercantil não é nova, mas sua função e lugar de mais-valia em relação ao saber, isto é, o lugar em que ela se situa na produção escolar como objeto destinado à satisfação imediata do Outro, seja em termos psíquicos ou materiais.

Como lembra Lajonquière (1999), a partir do momento em que "a instituição escolar passou a convocar a criança para um trabalho tão sério quanto ao do adulto” (p. 83), a escola deixou de suspender temporariamente o "valor de troca" que domina o imaginário social, isto é, o que a diferenciava do mundo adulto era um trabalho escolar como pura perda no presente. Esta perda era o que possibilitava outrora o "tempo de espera" para a criança, enquanto abertura para outros mundos, saberes e valores, que não só àqueles imbuídos do valor de produção. Tal tempo passou a ser vertido para o mercado do saber, onde impera a lógica da competividade, da produtividade, dos treinamentos escolares para os testes, em que a pedagogia se transforma ela mesma na destruição da curiosidade e da capacidade de pensar. Tal dispositivo só pode ser compreendido como expressão do trabalho da pulsão de morte.

Miller e Milner (2006) discutem o significante "avaliação" como marca de um "batismo burocrático" cuja essência é da ordem do "ciframento inaugural", isto é, como um correlato ao momento constitutivo da "marcação do homem pelo significante", em que o "sujeito natural, encontra-se barrado pelo significante e, em seguida, dotado do significante que o representa" (p. 26). Segundo os autores, o lugar central que a avaliação passou a ocupar na cultura implica o declínio de uma sociedade orientada em torno da lei, em direção à consolidação 
de uma sociedade orientada por contratos. A sociedade organizada em torno da lei não se baseia em uma relação entre equivalentes, na medida em que a lei instaura uma diferença, marca de um interdito que abre para outras possibilidades. Já a sociedade de contratos pressupõe uma relação imaginária entre iguais. Milner (Miller \& Milner, 2006) explica que, enquanto a "lei permite tudo o que ela não interdita expressamente", na sociedade de contratos, contrariamente, "o que não é expressamente permitido não é permitido de jeito nenhum" (p. 7), ou seja, somente é permitido o que está escrito e explícito, o que pode ser avaliado e mensurado. Tal condição retrata a coexistência da tradicional democracia fundada em torno da lei com a ideia de "democracia ilimitada”, esta fomentada pela ideologia do contrato, na qual nenhum problema ficaria sem solução, sem falta.

$\mathrm{O}$ autor explica que vivemos sob o "hiperparadigma da equivalência”, composto, no mínimo, por três paradigmas que se combinam e se copertencem: o problema-solução, a avaliação e o contrato. Estabelece-se que um problema oriundo da sociedade demanda ao político uma solução, sendo apresentada em termos de avaliação que, por sua vez, estabelece uma medida calculável e comparável entre um antes e um depois. O que há em comum entre tais paradigmas consiste na estrutura que se articula a partir da matematização da realidade e funciona por relações de equivalência e substituição. E o que se substitui? Substitui-se o problema pela avaliação e se faz acreditar que o simples fato de avaliar produz um valor correspondente à solução. Troca-se, assim, um problema por uma avaliação. $\mathrm{O}$ equivalente da avaliação, por sua vez, corresponde a um aspecto jurídico, o contrato, que pressupõe uma transação entre partes iguais. Assim, no hiperparadigma da equivalência se agrupam ao menos três paradigmas que se combinam que vão da "avaliação à estrutura problema-solução, mas também da avaliação à ideologia de contrato" (Miller \& Milner, 2006, p. 5). A fórmula problema-solução-avaliação-contrato surge com uma medida "salva-sociedade", em que o que é útil para a sociedade requer o sacrifício de alguns para o bem de todos, articulando a avaliação ao suposto avanço das democracias modernas. Talvez, em razão dessa característica "salva-sociedade", a avaliação tornou-se um discurso irrefutável, em que todos devem 
prestar contas de si, embora estejamos longe de produzir uma implicação do sujeito em relação a si próprio e ao Outro.

Miller (Miller \& Milner, 2006) entende que, enquanto a sociedade da lei supõe a presença de uma diferença estrutural, uma dissimetria, que implica o terceiro, ou, conforme postulou Lacan, o grande Outro barrado, a sociedade de contrato estabelece uma suposta relação entre iguais, uma relação simétrica e ilimitada, em que o contrato é "um esforço para dar um estatuto simbólico ao estádio do espelho" (Miller \& Milner, 2006, p. 7). A função antecipatória que Lacan apresenta na experiência especular de estruturação da subjetividade tem por finalidade tamponar o lugar de uma falta - falta de unidade corporal e do $\mathrm{Eu}$ - para dizer de outro modo, a falta que não se contabiliza na relação especular, mas que deverá ser inscrita pelo significante e recortada com a precipitação do objeto a - causa de desejo. E como sabemos, será justamente a presença dessa falta que possibilitará o funcionamento do sujeito desejante no processo de constituição subjetiva.

Podemos inferir que a lógica da avaliação desloca radicalmente a relação entre o Estado e as instituições escolares, na medida em que as tradicionais relações baseadas no mandato e na responsabilidade das autoridades educativas vão sendo substituídas pelos contratos de gestão e produtividade, avaliações de rendimento e metas. Dito de outro modo, no lugar da lei, ou do saber paterno, que encarnava a figura do professor como representante do grande Outro, surge o contrato, um tipo de controle matematizado pelo saber técnico, em que nada pode ficar de fora.

No entanto, a demanda por avaliação torna-se uma regra bem aceita nas instituições da sociedade, na medida em que ela promete dar aquilo que falta à instituição. Essa troca se faz com o consentimento do avaliado, na medida em que toda avaliação se estabelece um "contrato de confiança" no qual o sujeito se compromete, sem o saber, no processo de sua própria exclusão. Nas palavras de Miller (Miller \& Milner, 2006), "vocês mesmos terão aberto a porta para visitas e serão obrigados a dizer: 'Eu 
valho menos do que aquele ali', serão obrigados a dizer: 'Eu mereço a morte'. A avaliação visa a isso, a essa autocondenação do sujeito" (p. 26).

Na mesma perspectiva, Gori $(2011,2013)$ considera a avaliação como o nome da loucura social nesse início de século XXI. Segundo o autor, a avaliação não está voltada para a realidade das coisas, mas dirigida para legitimar a eficácia imaginária das aparências, legitimando o falso como lugar de verdade. A atual "avaliação-científica" pode ser pensada como uma "máquina de impostura”, impondo uma nova solução moral ao sujeito, isto é, a impostura, a mentira, o embuste como resposta às exigências normativas que demanda o Outro. O discurso de uma direitora testemunha os efeitos mortíferos de tal dispositivo no âmbito da escola, que produz a impostura como resposta, como meio para se atingir certos fins: "não critico as escolas que passam o gabarito para o aluno, sabe, elas estão sendo tão desonestas quanto esse sistema que está aí, não há crítica para isso. Eu acho muito dificil criticar uma postura como essa, porque eu acho que a gente está trabalhando num universo muito maior de desconsideração" (Passone, 2014a). O reconhecimento da impostura como valor moral por parte de nossa cultura está associado à produção de subjetividades capazes de operacionalizar o atual mundo inscrito pelo neoliberalismo.

O discurso avaliativo se conforma com o dispositivo normativo, no sentido foucaultiano, transformando o humano em recurso para aumentar o capital, destituído de ideias ou de quaisquer desejos que diferem do desejo de funcionalidade, de resultados. Segundo Gori (2013):

O desejo de dominação do mestre cedeu lugar ao desejo de domínio anônimo. Mas a natureza desse desejo de domínio, ao mesmo tempo massificado e fragmentado na sua expressão, permanece idêntica em relação à estrutura do mestre, do mestre antigo; esse mestre que Lacan nos diz que "não deseja saber absolutamente nada - ele deseja que as coisas andem". Se o poder do mestre subtrai do escravo seu saber, para tirar maior proveito próprio, na época moderna ele se apoia sobre as ciências e as técnicas, não para fazer avançar o cursor do saber, mais para controlar a natureza e o humano enquanto fundos energéticos a se explorar ao infinito. Esse desejo não resultou de uma demanda de amor 
ou da sede de saber, ele é simplesmente desejo de que as coisas funcionem, desejo de funcionalidade. (p. 24)

O procedimento de avaliação, como um meio capaz de dar valor às ações ou aos serviços, em que ela mesma torna-se o seu próprio fim, desconhece os resultados que produz. Ao produzir referências de valor a partir da razão técnica, ou instrumentalista, como diz Adorno, não deixa lugar para o verdadeiro ou justo, pois vigora somente uma enunciação de valor: se "isso" funciona ou não, mais ou menos.

O valor passa a ser determinado por meio da racionalidade prático-formal, em detrimento de outras formas de racionalidades, como a teórica, a conceitual, a substancial e a racionalidade mítico-poética. A racionalidade prático-formal, como entendida por Weber, é a racionalidade do direito e dos negócios cujas formas se agrupam conforme os fins e os interesses individuais, com ênfase nos procedimentos e nas normas que visa à eficiência e à burocratização das instituições e organizações sociais, em que a racionalidade técnica ou instrumental passa a definir as condutas e os costumes morais, distanciando-se das noções antropológicas de valor. Em suma, a avaliação produz um valor associado à trajetória de produção, ao mesmo tempo que adapta o comportamento e as formas de pensar; um dispositivo de distribuição racional dos lugares e relações dos indivíduos na sociedade, uma nova forma de "servidão vountária”.

\section{O que promete a avaliação no campo educacional?}

A avaliação promete a educação ideal, isto é, uma educação sem falta e um ensino sem resto, deixando o aluno e o professor indefesos quanto ao gozo do Outro. O que pede os avaliadores ao professor? Que este possa preencher o vazio do aluno com seu conhecimento. $\mathrm{O}$ que pede a avaliação ao aluno? Que este possa produzir-se como objeto que venha satisfazer a falta do Outro. Essa satisfação é sempre de cunho narcísico, imaginário, o que implica uma criança ocupar esse lugar de ser objeto do desejo do outro, de saber que é desejado ou não pelo outro, de ser amado ou não, ser admirada ou não; um lugar de tudo ou nada, de vida ou morte para o sujeito. Podemos dizer, a partir desse lugar, que a avaliação reproduz o momento 
inaugural que articula o gozo ao significante, reproduzindo o ciframento do sujeito, mas marcado pela lógica dos equivalentes, da estatística e das metas, isto é, enquanto um valor mais ou menos satisfatório, de acordo com a avaliação da moda, caminho aberto para normalização dos indivíduos e submissão em massa dos mais novos aos ideais mercadológicos.

Desse modo, o discurso avaliativo retrata a ilusão de controle sobre o saber impossível da educação, isto é, sobre a demanda escolar e do desejo de saber do aluno. Como fonte de ilusão, a avaliação se coloca como única realidade à pergunta constitutiva do sujeito: o que quer o outro de mim? A demanda avaliativa se apresenta como verdade à questão do sujeito. Na medida em que o discurso avaliativo promete fornecer no real essa resposta, suprime-se a falta necessária implícita na demanda educativa. Em outras palavras, a avaliação não possibilita a denegação da demanda do Outro, transformando o real educacional em um imaginário pedagógico mensurável e objetivo. Paralelamente, a avaliação implica a construção de um standard que constrói um sujeito cognoscente suposto normal, que, por contraste, produz o que se desvia desse padrão (Jerusalinsky, 1999). Dessa forma, a avaliação concebe um lugar ao indivíduo, que ao ser avaliado, passa a "rotulado" segundo a lógica do objeto fetiche e da "contabilidade" do gozo no sistema de serviços do Estado.

Maud Mannoni (1976), em seu clássico trabalho Educação impossivel, alertava para o "erro de excluir o administrativo do campo de análise", lembrando-nos da força de monopólio da dimensão econômica que com outros saberes técnicos tornam-se fonte de todos os tipos de abusos de poder. Em suas palavras, "logo que a preocupação de rendimento é primacial, desaparece o interesse humano do empreendimento" (p. 20). De modo análogo opera a obsessão pelos ideais almejados pelos avaliadores e pedagogos na educação, como diz Mannoni, uma proposta pedagógica que impõe de início "o ideal a atingir não pode deixar de menosprezar o que toca à verdade do desejo (da criança e do adulto). Expulsa do sistema pedagógico, esta verdade retorna sob forma de sintoma e exprimir-se-á 
na delinquência, na loucura e nas diversas formas ditas de inadaptação" (p. 50). Em outras palavras, a educação ideal nega a "verdade" do desejo e impõe ao aluno um mandato imaginário que o priva de uma possibilidade real de escolha. O imaginário pedagógico atual se revela pleno de práticas que encarnam a dita educação ideal, isto é, que se propõe a fabricação de um aluno ideal, impossibilitando o reconhecimento singular do sujeito no circuito da palavra e do desejo.

Diante dos obstáculos do ensino e da transmissão, bem como do desinvestimento da aprendizagem, o imaginário pedagógico nacional utiliza certo vocabulário para justificar e conjugar a sorte, segundo a moda pedagógica, levando os alunos a se tornarem categorias. O rendimento esperado do aluno, implícito nos sistemas de avaliação, conforme algumas denominações taxinômicas, tais como "básico", "adequado" ou "avançado", também revela a lógica de proporcionalidade fundamentada na psicobiologia naturalista do desenvolvimento da criança. Aprofundase, assim, o império do discurso e da "ilusão (psico)pedagógica" que, como sabemos, trata-se de uma crença na proporcionalidade entre a intervenção educativa e o desempenho a priori esperado em termos cognitivos e comportamentais. Tal forma de se pensar a problemática educativa passa a ser considerada natural e não levanta suspeita sobre seus efeitos nefastos, a saber, a busca por metas impossíveis que "reforça uma série de sintomas efeitos discursivos da pedagogia moderna, que acabam, invariavelmente, reforçando a psicologização do cotidiano escolar" (Lajonquière, 1999).

A produção de subjetividades que, como pensado por Foucault, considera o indivíduo como um produto de técnicas de subjetivação, referente aos modos históricos de civilização e poder, demonstra os modos próprios de alienação que oferece uma cultura, isto é, como uma cultura desenvolve formas as quais o sujeito encontra os meios de identificação. Radicalmente diferente é o sujeito na psicanálise, este que, por seus sintomas, tende a evadir das imputações culturais e de seus modos de civilização. $\mathrm{O}$ sujeito nesse caso não é idêntico às identificações que a civilização the impõe, mas, ao contrário, o sujeito é esse que faz sintoma, objeção aos constrangimentos e às imposições sociais, isso que resta irredutível a toda forma de normatização. 
De outro modo, a força e profundidade da descoberta freudiana consiste em mostrar que, na análise dos sintomas neuróticos, o lugar de existência do sujeito se encontra nas suas disfunções, e não na sua aderência à ordem social, no cruzamento entre o que é comum e o que é próprio de cada um. Aqui, podemos nos interrogar se a condição de desistência e revolta do aluno não implica justamente o acontecimento do sujeito diante do real das estratégias técnicas e metodológicas do sistema e dos professores? Por um lado, o estilo de cada aluno, por outro, as estratégias normalizadoras e homogeneizantes dos ideais educacionais, em que o aluno passa a ser identificado com o resultado e rotulado de acordo com os padrões avaliativos. O sujeito que tenta responder à demanda impossível e desproporcionada da política educacional ao custo de sua própria singularidade.

A resposta de cada um à demanda avaliativa determinará o efeito mais ou menos nocivo ou estéril dessa educação. Nesse sentido, podemos dizer que a avaliação é um significante de nossa modernidade que vem acompanhado por outro significante, o "fracasso escolar", como produto dos laços sociais e discursos produzidos no campo escolar. O fracasso escolar é ressignificado pela psicanálise, podendo ser entendido como estilo do sujeito contra a tecnologia de ensino que o transforma em objeto. Assim, o fracasso escolar produzido pelas avaliações em massa retrata a tentativa do sujeito em se separar do Outro (Estado, família, escola), na medida em que, ao mesmo tempo que o sujeito é alienado ao significante do Outro (A), ele também sofre o empuxo à separação justamente por aquilo que causa seu desejo.

Por que se demanda aos governantes, educadores e analistas que encontrem soluções, respectivamente, aos problemas da sociedade, ao ineducável e ao sofrimento psíquico? Porque há sempre um a mais que escapa da lógica dos equivalentes, da lógica problema-solução, ou seja, há sempre um objeto que excede e escapa a qualquer forma de avaliação, marca irredutível do inconsciente, que resiste à padronização estabelecida pela 
“unidade contável". Como observam Miller e Milner (2006): "Por que educar é impossível? Porque se demanda ao educador substituir com o pleno de seus conhecimentos o vazio da ignorância daquele a ser educado. Ora, dirá Freud, eduquem como quiserem, haverá sempre alguma coisa que não poderá ser substituída" (p. 10).

Dessa maneira, segue a premissa de que o fracasso educacional retrata o acontecimento do sujeito na estrutura, isto é, por ser sintoma disso que falha, o sujeito resiste. Se por definição o real é o simbólico que fracassa, exatamente por ser impossível de inscrever e ordenar o real, então o fracasso pode ser pensado como a dimensão simbólica (sujeito) que retorna como resposta no real, como tentativa de separação do Outro social (Passone, 2013a). Um elogio ao fracasso, como diz Éric Laurent (2005), não uma apologia, mas um modo ímpar de fracasso que não possui do outro lado do espelho o sucesso como oposto complementar.

Seja como for, a educação por metas e resultados encarna os termos de uma cruzada, com a missão de "salvar" os mais novos da ignorância, tendo no modelo atual de avaliação um poderoso mecanismo de adaptação e eliminação, quando menos, apresenta-se como obstáculo à educação, por mais paradoxal que aparente, pois tudo se faz em nome do direito da criança e da qualidade do ensino.

THE PRODUCTION OF THE SCHOOL FAILURE AND THE EVALUATIVE FUROR: DOES THE SUBJECT RESIST?

\section{Abstract}

Thinking school failure as a subject event subverts the speech of the failure largely produced by the "standard" evaluation ghost in education management. In this perspective, the evaluative furor and the speeches about the effectiveness and quality of educational systems as devices for social domestication of the young ones who end up increasing the psychologizing and the medicalization in the everyday school life are questioned.

Index terms: educational assessment; school failure; education; psychoanalysis.

PRODUCCIÓN DEL FRACASO ESCOLAR Y EL FUROR DE LA EVALUACIÓN: ¿RESISTE EL SUJETO?

\section{Resumen}

Pensar el fracaso escolar como un acontecimiento del sujeto subvierte el discurso del fracaso producido en gran medida por el fantasma de la evaluación "standard" en la gestión de la enseñanza. En esta perspectiva, se interrogan el furor de la evaluación y los discursos acerca de la eficacia y la calidad de los sistemas educativos, como dispositivos de domesticación social de los más nuevos que terminan por aumentar la psicologización y la medicalización de la vida escolar cotidiana.

Palabras clave: evaluación educativa; fracaso escolar; educación; psicoanálisis. 


\section{REFERÊNCIAS}

Birman, J. (2014). O sujeito da diferença e a multidão. Revista Ide, 36 (57), 25-40.

Bonamino, A., \& Sousa, S. Z. (2012). Três gerações de avaliação da educação básica no Brasil: interfaces com o currículo da/na escola. Educação e Pesquisa, 38 (2), 373-388. doi: http://dx.doi.org/10.1590/S1517-97022012005000006

Brooke, N. (2008). Responsabilizaçáo educacional no Brasil. Revista Iberoamericana de Evaluación Educativa, 1 (1), 93-109.

Brooke, N. (2013). Sobre a equidade e outros impactos dos incentivos monetários para professores. Estudos em Avaliação Educacional, 24 (55), 34-62. doi: http:// dx.doi.org/10.18222/eae245520132719

Dufour, D.-R. (2005). A arte de reduzir as cabeças: sobre a nova servidão na sociedade ultraliberal. Rio de Janeiro, RJ: Companhia de Freud.

Enriquez, E. (1990). Da horda ao Estado: psicanálise do vínculo social. Rio de Janeiro, RJ: Zahar.

Foucault, M. (1999). Vigiar e punir: nascimento da prisão. Petrópolis, RJ: Vozes.

Freitas, L. C. (2013). Responsabilização, meritocracia e privatização: conseguiremos escapar ao neotecnicismo. In I. Pino, D. Zan (Orgs.), Plano Nacional da Educação (PNE): questôes desafiadoras e embates emblemáticos. Brasília, DF: Inep.

Freitas, L. C. (2014). Os reformadores empresariais da educação e a disputa pelo controle do processo pedagógico na escola. Educação \& Sociedade, 35 (129), 1085-1114. doi: http://dx.doi.org/10.1590/ES0101-73302014143817

Freud, S. (1996). Análise terminável e interminável. In S. Freud, Edição standard brasileira das obras psicológicas completas de Sigmund Freud (J. Salomâo, trad., Vol. 23, pp. 225-74). Rio de Janeiro, RJ: Imago. (Trabalho original publicado em 1937)

Gori, R. (2011). Une nouvelle manière de donner des ordres? In A. Abelhauser, R. Gori, \& M. J. Sauret, La folie évaluation: les nouvelles fabriques de la servitude. Paris, France: Mille et Une Nuits.

Gori, R. (2013). La fabrique des imposteurs. Paris, France: Les Liens Qui Liberent.

Jerusalinsky, A. (1999). Psicanálise e desenvolvimento infantil: um enfoque transdisciplinar. Porto Alegre, RS: Artes e Ofícios.

Lacan, J. (1997). O seminário, livro 7: a ética da psicanálise, 1959-1960. Rio de Janeiro, RJ: Jorge Zahar.

Lacan, J. (2008). O seminário, livro 16: De um Outro ao outro, 1968-1969. Rio de Janeiro, RJ: Jorge Zahar.

Lajonquière, L. de (1999). Infância e ilusão (psico)pedagógica: escritos de psicanálise e educação. Petrópolis, RJ: Vozes.

Laurent, E. (2005). O Nome-do-Pai entre realismo e nominalismo. Opção Lacaniana - Revista Brasileira Internacional de Psicanálise, (44), 92-109.

Machado, R. (2001). Zaratustra tragédia nietzschiana. Rio de Janeiro, RJ: Zahar.

Manonni, M. (1976). Educação impossivel. Lisboa, Portugal: Moraes.

Miller, J. A., \& Milner, J. C. (2006). Você quer mesmo ser avaliado? São Paulo, SP: Manole.

Nietzsche, F. (1985). Crepúsculo dos ídolos. Lisboa, Portugal: Edições 70. 
Passone, E. F. K. (2013a). Fracasso na implementação de políticas educacionais: sintoma e emergência do sujeito. Estilos da Clínica, 18 (1), 53-70. doi: http:// dx.doi.org/10.11606/issn.1981-1624.v18i1p53-60

Passone, E. F. K. (2013b). Psicanálise e educação: o discurso capitalista no campo educacional. ETD - Educação Temática Digital, 15 (3), 407-424.

Passone, E. F. K. (2014a). Da avaliação da educação básica aos incentivos por resultados: uma abordagem pelo discurso psicanalítico. Relatório de Pesquisa. São Paulo, SP: FAPESP.

Passone, E. F. K. (2014b). Incentivos monetários para professores: avaliação, gestão e responsabilização na educação básica. Cadernos de Pesquisa, 44 (152), 424-449. doi: http://dx.doi.org/10.1590/198053142864

Pontual, C. T. (2008). Remuneração por mérito: desafio da educação. São Paulo, SP: Fundação Lemann.

Ravitch, D. (2010). Vida e morte do grande sistema escolar americano: como os testes padronizados e o modelo de mercado ameaçam a educação. Porto Alegre, RS: Sulina.

Tyszler, J. J. (2014). O fantasma na clinica psicanalitica. Recife, PE: Editora do Tradutor.

\section{NOTAS}

1. Projeto de pós-doutorado desenvolvido na Faculdade de Educação da Universidade de São Paulo (FEUSP) entre 2013 e 2015, no âmbito do Laboratório de Estudos e Pesquisas Psicanalíticas e Educacionais sobre a Infância (LEPSI). Agradecemos o apoio da Fundação de Amparo à Pesquisa do Estado de São Paulo (Processo FAPESP Número: 13/02840-6) e a supervisão do professor titular Leandro de Lajonquière (FEUSP/Paris VIII-França).

2. Em busca da escolarização de um número maior de alunos, João Batista de La Salle (1651-1719) sistematizou o método simultâneo de ensino preconizado por Comênio, quando todas as atividades da escola passaram a seguir o "princípio de vigilância”, como apresentado por Foucault (1999).

ericpassone@yahoo.com.br

Rua Papa Leão XIII, 10/03

13082-793 - Campinas - SP - Brasil.

Recebido em março/2015. Aceito em outubro/2015. 